\title{
Imperfect durability and the Coase Conjecture
}

\author{
Raymond Deneckere * \\ and \\ Meng-Yu Liang**
}

This paper considers a market served by a monopolist who sells a durable goods that depreciates stochastically over time. We show that there exist three types of stationary equilibria: a Coase Conjecture equilibrium, a monopoly equilibrium and a reputational equilibrium. When the depreciation rate is low, the Coase Conjecture equilibrium is the unique equilibrium. For intermediate values of the depreciation rate, all three equilibrium types coexist. When the depreciation rate is high, the monopoly equilibrium is the unique equilibrium. Consequently, when selling a good of sufficiently low durability, the monopolist does not lose any of her monopoly power. Furthermore, the steady state output in the reputational equilibrium falls below the monopoly quantity. Hence in durable goods markets welfare losses due to monopoly power may be larger than in markets for perishables.

\section{Introduction}

Durable goods make up a significant fraction of GNP and play an important role in the generation and propagation of the business cycle. As a consequence, the special nature of durable goods markets has drawn considerable interest from economists. One issue that has received a lot of attention is whether a durable goods monopolist has the ability to exercise market power. Indeed, Ronald Coase (1972) has argued that a monopoly seller of a perfectly durable good will be unable to exercise any monopoly power unless she can precommit to a production schedule. Coase's logic is that a durable goods monopolist faces an irresistible temptation to keep on cutting her price in order to further penetrate the market. Unless there is a limitation on the rate at which the good can be produced, the competitive outcome will be achieved "in the twinkling of an eye" (Coase,

\footnotetext{
*University of Wisconsin-Madison; rjdeneck@wiscmail.wisc.edu

**Academia Sinica; myliang@econ.sinica.edu.tw
} 
1972).

Coase's logic has proven to be extremely robust. Stokey (1981), Fudenberg, Levine and Tirole (1985) and Gul, Sonnenschein and Wilson (1986) have formalized Coase's intuition under the assumption that the monopolist's product has infinite durability. More precisely, this literature has shown that in stationary equilibria the monopolist cannot make sales at prices significantly greater than her marginal cost of production (or the lowest buyer valuation, whichever is higher), provided the length of time that elapses between successive price setting periods is sufficiently small. Bond and Samuelson (1984) have demonstrated that Coase's logic extends to products of limited durability, by constructing a stationary equilibrium that satisfies the Coase Conjecture, even when the durability is arbitrarily low.

Coase's prediction presents somewhat of an empirical puzzle, as there does not seem to be any systematic evidence that durable goods monopolists make less profits, or price at lower margins, than their nondurable counterparts. For example, two of the most profitable monopolies in the US, Microsoft in the market for software, and Intel in the market for microprocessors, sell durable goods. Their prices also appear far above the marginal cost of production (which is near zero for software).

Furthermore, if the Coase Conjecture forces significantly constrained the profitability of durable goods manufacturers, we should observe a variety of responses aimed at restoring this profitability, such as leasing, the adoption of most-favoured nation clauses (Butz, 1990) or significant reductions in the durability of the product offered for sale (Bulow, 1986). While such responses do indeed occur, their adoption seems less widespread than theory would predict.

This evidence also presents a theoretical challenge, as in markets served by durable goods monopolies or oligopolies, departures from the competitive outcome can only be explained by lack of patience on the part of manufacturers (which seems hard to justify), the presence of myopic consumers (which is only defensible for consumer durables, and seems to be at variance with available evidence (Chevalier and Goolsby, 2005)), the existence of commitment power (but then the solution is time inconsistent), or the concern for reputation ((Ausubel and Deneckere (1989), Bond and Samuelson (1987), but this requires nonstationary equilibria). Furthermore, the theoretical prediction that the monopoly outcome obtains whenever the good is non-durable, yet the competitive outcome results whenever the good is durable, no matter how quickly it depreciates, seems unappealing.

In an interesting contribution, Karp (1996) provides a potential resolution to these puzzles. 
Karp constructs continuous time equilibria for a model with imperfect durability, and shows that the monopolist can earn profits above the competitive level. However, since there always exists a Coase Conjecture equilibrium in his model, proponents of Coase's logic could still argue that there should be no presumption that monopoly results in welfare losses, even in markets for products of relatively low durability.

The current paper studies an infinite horizon discrete-time model of price setting by a monopolist selling a good of finite durability. We establish that when the depreciation factor is sufficiently high, a Coase Conjecture equilibrium never exists. More strikingly, above a certain threshold for the depreciation factor, there is a unique stationary equilibrium, in which the monopolist charges the monopoly price in every period. This equilibrium continues to exist even when the seller becomes arbitrarily patient. Thus, when the product is of sufficiently low durability, the monopoly outcome necessarily obtains. The intuition for this result runs as follows. Coase's logic is that with infinitely durable goods, the monopolist is always tempted to sell additional output until every consumer has been served. However, when the product depreciates, old customers who value the good considerably above average reenter the market whenever the product fails. When the depreciation factor is sufficiently high, selling at a relatively high price to replacement demand is more profitable than lowering the price in an effort to further penetrate the market.

When the good is of sufficiently high durability, we establish that the Coase Conjecture equilibrium is the unique equilibrium of our model. However, in this case we show that the manufacturer has an incentive to reduce the durability of the product to a level sufficiently low to destroy the Coase equilibrium. Thus, our model can potentially explain the empirical puzzle described above: Either the inherent durability of the product is low enough that the manufacturer can fully exercise his market power, or else the manufacturer can restore his margins and profitability through planned obsolescence (or any of the other techniques described above). Indeed, the evidence suggests that such practices are more prevalent when the inherent durability of the good is high.

For example, textbook publishers produce new editions of popular texts on an accelerated schedule, in order to increase their economic depreciation (Waldman, 2003). In the software example mentioned earlier, the physical durability of the product is essentially infinite, but sellers introduce frequent new versions, which produces economic depreciation. Strong network externalities, discontinuation of support for older versions, and the introduction of new file formats combine to make old software essentially useless to most buyers. There is also evidence that short-term leasing is prevalent for assets that are long lived (commercial aircraft, mainframe computers, copying 
machines). Finally Palacios-Huerta and Saracho (2004) report that industries selling products of higher durability employ longer term managerial compensation schemes, that are more positively sensitive to profits, and more negatively sensitive to sales, in order to give managers increased commitment abilities. ${ }^{1}$

From a theoretical perspective, our paper contributes by developing a novel method for constructing stationary equilibria of the discrete-time game. Using this construction, we are able to completely characterize the set of stationary equilibria for the special case where consumers' valuations take on only two possible values. We show that, depending upon the parameters, three types of stationary equilibria can exist: a Coase Conjecture equilibrium, a monopoly equilibrium, and a "reputational" equilibrium. The Coase Conjecture equilibrium exists for sufficiently low values of the depreciation factor, and is characterized by a decreasing price path, and a unique steady state equal to the competitive quantity. The monopoly equilibrium exists for sufficiently high values of the depreciation factor, and has the seller charging the static monopoly price in every period. For intermediate values of the depreciation factor, all three equilibrium types coexist. In the reputational equilibrium, the steady state quantity falls below the monopoly quantity. Were the monopolist to increase sales beyond this level, equilibrium play would revert to the Coase Conjecture equilibrium. An important message therefore emerges from our analysis: in markets for durable goods monopoly power may result in higher margins and larger welfare losses than in markets for perishable goods.

For general "neoclassical" demand functions, our method for constructing stationary equilibria still works, but a complete characterization of the set of stationary equilibria as a function of the parameters becomes unwieldy. Nevertheless, we are able to provide an existence result, and show that the qualitative properties of the two-step demand case generalize to this class.

Surprisingly, the literature on monopoly in markets for new products with imperfect durability is relatively sparse, consisting mainly of contributions by Bond and Samuelson $(1984,1987)$, Sobel (1991) and Karp (1996). These papers overlap with ours to varying degrees, but none of them provide a complete analysis of the set of stationary equilibria. We defer a detailed discussion of the similarities and differences between the various models and their results to Section 6 .

The rest of the paper is organized as follows. Section 2 describes a two-type model where resale is allowed, and introduces the equilibrium concept. Section 3 characterizes the steady states

\footnotetext{
${ }^{1}$ Our results also admit an alternative interpretation of the evidence. We show that a monopoly equilibrium always exists when players are sufficiently patient. Thus when this condition holds, durable goods producers need not earn any less than their nondurable counterparts.
} 
of stationary equilibria. Section 4 describes the construction of the stationary equilibria, and delineates when each type of equilibrium exists. Section 5 generalizes the analysis to general Nstep demand functions. Section 6 considers endogenous choice of durability. Section 7 discusses the related literature, and Section 8 concludes. Important proofs are relegated to an Appendix; the remaining proofs are available as a online Appendix (http://idv.sinica.edu.tw/mliang/Papers.htm).

\section{The Model}

Consider a market for an imperfectly durable good which depreciates stochastically along a continuous time path, but is offered for sale at discrete points in time, spaced a length of time $z>0$ apart. The durable good is indivisible and provides either full services or no service at all. The probability that the good is still working after a length of time $t \in R_{+}$equals $e^{-\lambda t}$. Letting $\mu$ denote the probability that the good depreciates within one period, we therefore have:

$$
\mu=1-e^{-\lambda z}
$$

The market is populated by a continuum of infinitely-lived consumers, indexed by $q \in I=[0,1]$. All consumers are risk neutral and have the same discount rate $r$. Each consumer wishes to possess at most one unit of the durable good. ${ }^{2}$ We assume that the flow benefit of the services consumer $q$ derives from owning one unit of the durable good is described by the following inverse demand function:

$$
F(q)=\left\{\begin{array}{ll}
a, & \text { if } q \in[0, \hat{q}] \\
b, & \text { if } q \in(\hat{q}, 1]
\end{array}, \text { where } a>b>0 \text { and } 0<\hat{q}<1 .\right.
$$

Our reason for initially focusing on the two-type case is twofold. First, in order to construct stationary equilibria and analyze their properties, we use the method of 'backward induction on the state', starting from any potential steady state. Unlike in the model without depreciation,

\footnotetext{
${ }^{2}$ We assume that a consumer's value of posessing an extra unit is zero when the first unit is still working. Nevertheless, consumers may still wish to hold more than one unit, so as to guard against the possibility that the good would cease to perform before the next trading opportunity arises. However, if the length of the time period is sufficiently small and the marginal cost of production is positive, consumers will never choose to do so. This is because the expected value of holding a second unit converges to zero as the length of the time period shrinks to zero.

When the lengh of the time period is large, the expected value of holding a second unit may exceed the marginal cost of providing it. In this case, we assume that the storage cost for holding a second unit are infinite. Alternatively, we could treat the demand for the second unit as a demand for the first unit by a fictitious consumer.
} 
this method only works for the finite type case. In addition, the two-type model allows us to provide simple closed-form solutions for the equilibria, and to bring out the economics in the most transparent way possible. We analyze the general $N$ - type case in Section 5 .

Let $f(q)$ denote consumer $q$ 's willingness to pay for the privilege of a one-time opportunity of acquiring one unit of the durable good. That is,

$$
f(q)=\int_{0}^{\infty} F(q) e^{-(\lambda+r) s} \mathrm{~d} s= \begin{cases}\bar{v}, & \text { for } q \in[0, \hat{q}] \\ \underline{v}, & \text { for } q \in(\hat{q}, 1]\end{cases}
$$

where $\bar{v}=\frac{a}{r+\lambda}$ and $\underline{v}=\frac{b}{r+\lambda}$. Thus, if the price at time $t$ is $p$, then by purchasing or selling a unit of the durable good (and never transacting thereafter), consumer $q$ can derive a net surplus of $e^{-r t}(f(q)-p)$ or $e^{-r t}(p-f(q))$, respectively.

A consumer is allowed to access the market as often as she wishes. Consumers seek to maximize the present value of their expected net surplus over all possible trading decisions, as a function of their holding status.

The market is served by a monopolist whose marginal cost of production, $c$, is constant and less than $\frac{b}{r+\lambda}$. Without loss of generality, we normalize $c$ to zero. The monopolist seeks to maximize the net expected present value of profits, using the same discount rate as consumers, $r$.

Sales occur at times $t=0, z, 2 z, \ldots, n z, \ldots$, and neither the monopolist nor consumers are allowed to trade at any time $t \in(n z,(n+1) z)$. We will refer to the time $t=n z$ as "period $n$ ". The timing of play within each period is as follows. Before trade, the monopolist selects a price, $p$. Then consumers can trade (buy or sell) with the monopolist at the price $p$, or choose not to trade. After trade occurs, a time interval of length $z$ elapses, after which play is repeated.

Note that the monopolist is allowed to repurchase some of the stock of the durable. However, in the class of stationary equilibria (to which the analysis in the paper is confined) the monopolist always has net positive sales in every time period, even when the price is rising over time. Hence, all of our results hold for a model in which the monopolist is not allowed to buy back, and instead a competitive second-hand market is operative at trade time in every period. ${ }^{3},{ }^{4}$

\footnotetext{
${ }^{3}$ In this case, the monopolist's maximization problem in equation (3) below becomes $R(x)=\max _{y \in[x, 1]}\{P(y)(y-$ $x)+\delta R((1-\mu) y)\}$.

${ }^{4}$ If the monopolist is not allowed to buy back, and no competitive second hand market exists, the game would be much more complicated, as the state variable then becomes the distribution of current holdings, rather than just the size of current stock. Importantly, the qualitative nature of the equilibria changes, as they necessarily become cyclical whenever the good does not depreciate too quickly (Deneckere and Liang, 2005). However, the main message of the
} 
Following Gul, Sonnenschein and Wilson (1986), we are interested in stationary equilibria of this game. For our context, we define a stationary equilibrium to be a subgame perfect equilibrium in which consumers' strategies in each period depend only on the current market price. Note that this implies that a consumer's decision on whether or not to hold the durable for the next period is unrelated to his current holding status. Thus, in a stationary equilibrium a consumer's holding status after trade is described by a non-increasing left-continuous acceptance function $P(\cdot)$, with consumer $q$ choosing to hold a durable in the current period if and only if the monopolist's current price satisfies $p \leq P(q)$.

Since in our model the durable good depreciates randomly at the individual level, the set of remaining buyers before trade, will (with probability one) not be an interval. However, stationarity implies that the set of remaining buyers after trade is an interval of the form $(q, 1]$.

The acceptance function $P(\cdot)$ acts as a static demand curve for the monopolist, who faces a trade-off between less intertemporal price discrimination and delaying trade. Let $x \leq 1-\mu$ denote the total stock in the market before trade, and for $x \in[0,1-\mu]$ let $R(x)$ denote the monopolist's net present value of profits when the acceptance behavior of consumers is governed by $P(\cdot)$; then this trade-off is captured by the dynamic programming equation:

$$
R(x)=\max _{y \in[0,1]}\{P(y)(y-x)+\delta R((1-\mu) y)\},
$$

where $\delta=e^{-r z}$ is the discount factor between periods. To understand equation (3), note that when the monopolist brings the state after trade to $y$ by charging the price $P(y)$, then her net sales are given by $y-x$. The total stock in the market at the beginning of the next period will be $(1-\mu) y$, since (by the law of large numbers) a fraction $\mu$ of the stock $y$ will have depreciated. The monopolist then receives the continuation value $R((1-\mu) y))$ with one period delay.

Let $T(x)$ be the argmax correspondence in (3). By the generalized theorem of the maximum (Ausubel and Deneckere (1989, p. 527)) and the contraction mapping theorem, there exists a unique continuous function $R(\cdot)$ satisfying $(3)$, and $T(\cdot)$ is a non-empty and compact-valued correspondence. Furthermore, the supermodularity of the objective function in (3) implies that $T(\cdot)$ is a non-increasing correspondence. Let $t(x)=\min T(x)$ denote the monopolist's equilibrium choice. ${ }^{5}$

current paper survives: when the depreciation rate is sufficiently large monopoly is the unique equilibrium outcome, and when the depreciation rate is sufficiently low, the Coase Conjecture equilibrium is the unique equilibrium.

${ }^{5}$ Since $T(\cdot)$ is non-decreasing, there are at most a countable number of points for which $T(\cdot)$ is multi-valued. It follows from the consumer indifference equation (4) below that in equilibrium, in any period but the initial one, the monopolist must select $t(y)$, even when $T(y)$ is not single-valued (for details, see Ausbel and Deneckere (1989)). 
Note that $t(\cdot):[0,1-\mu] \rightarrow \mathbb{R}_{+}$is a left-continuous non-decreasing function. ${ }^{6}$ Let

$$
\rho=\delta(1-\mu)
$$

In order for the consumer's acceptance function to be consistent with consumer optimization, the following indifference equation must hold:

$$
f(q)-P(q)=\rho(f(q)-P(t((1-\mu) q))), \quad \text { for all } q \in[0,1]
$$

To interpret (4) observe that the above equation implies $(1-\rho) f(q)=P(q)-\rho P(t((1-\mu) q))$. The right-hand side of this equation is the consumer's cost of holding the durable for one period when the monopolist's current price is $P(q) .^{7}$ Meanwhile, for any consumer $q^{\prime}$ the benefit of holding the good for one period is $(1-\rho) f\left(q^{\prime}\right)$, which is monotone in $q^{\prime}$. Thus if $q^{\prime}<q$ consumer $q^{\prime}$ is willing to hold the good for one period, while if $q^{\prime}>q$ consumer $q^{\prime}$ is willing to forego holding the good for one period.

The triplet $\{P(\cdot), R(\cdot), t(\cdot)\}$ completely describes a stationary equilibrium. A stationary equilibrium path has the following structure. In the initial period, the monopolist selects a price $P\left(y_{0}\right)=P(t(0))$ and all consumers $q \leq y_{0}$ purchase. $^{8}$ At the beginning of the next period, a stock $x_{1}=(1-\mu) y_{0}$ remains, the monopolist selects a price $P\left(y_{1}\right)=P\left(t\left(x_{1}\right)\right)$, and all consumers $q \leq y_{0}$ decide to hold the durable (either by purchasing, or holding on to the unit they currently hold). This process continues until the stock reaches a steady state level $y_{s}$, at which point the monopolist ceases any attempt to further penetrate the market, and continues by fulfilling the replacement demand $\mu y_{s}$.

\section{Characterization of Steady States}

Our method of constructing stationary equilibria and proving existence must overcome several difficulties that are absent in the model with infinite durability. First, when there is depreciation,

\footnotetext{
${ }^{6}$ The left-continuity of $t(\cdot)$ follows from the upper hemi-continuity of $T(\cdot)$, the monotonicity of $T(\cdot)$ and the definition of $t(\cdot)$.

${ }^{7}$ Indeed, if the consumer does not currently hold the good, he must purchase it at a price $P(q)$. Next period, if the good is still alive, which occurs with probability $(1-\mu)$, he can sell it at a price $P(t((1-\mu) q))$. If the consumer currently holds the good, then he could sell it at a price $P(q)$, but by doing so would forego the opportunity of selling it next period at the price $P(t((1-\mu) q))$, whenever the good is still alive. Thus, the right-hand side of (4) still represents the correct opportunity cost of holding the good for one period.

${ }^{8}$ In the non-generic situation where $T(0)$ is multiple valued, the monopolist may select randomly from the set $P(T(0))$.
} 
the state need not always move forward (and indeed, in some equilibria it does not: in some periods the monopolist sells less than the amount the stock depreciates). Secondly, there may be multiple stationary equilibria that coexist for given values of the parameters, and even in a single equilibrium there exist multiple steady states. Finally, the usual method of backward induction on the state fails because given a stationary equilibrium on a subset of states, the extension to a stationary equilibrium on the whole state space is not unique.

Our solution to these difficulties is to backward induct from a steady state, carefully keeping track of any multiplicities in continuation that may exist. Depending on the case, backward induction on the state leads us to extend forward in the state space, or backward in the state space. To prove existence, we show that only three possible equilibria can arise, and characterize the parameter values for which each type occurs.

To backward induct, we first need to characterize the set of steady states that can be associated with any stationary equilibrium. Formally, a steady state is defined as a stock level $y_{s}>0$ satisfying $t\left((1-\mu) y_{s}\right)=y_{s} \cdot{ }^{9}$ Our first result establishes that such a steady state always exists.

Lemma 1 In any stationary equilibrium, there exists at least one steady state, i.e. there exists $y_{s} \in(0,1]$ such that $t\left((1-\mu) y_{s}\right)=y_{s} . \quad$ Furthermore, the steady state price must satisfy $P\left(y_{s}\right)=$ $f\left(y_{s}\right)$.

The intuition behind the existence of a steady state is that because the monopolist's objective function is supermodular, the policy function $t(x)$ is nondecreasing. As a consequence, optimal trajectories must be monotone, which rules out cycles, and guarantees the existence of a steady state. $^{10}$

When selling a perfectly durable good, the monopolist cannot resist penetrating the market fully, resulting in a steady state $y_{s}=1$. Indeed, if there existed a steady state $y_{s}<1$, the monopolist could profitably deviate by cutting the price to $\underline{v}$, thereby leading all remaining customers in the interval $\left(y_{s}, 1\right]$ to purchase. However, when the good depreciates, the monopolist may choose not to fully penetrate the market, leading to the existence of a steady state $y_{s}<1$. The reason the monopolist may be willing to do this is that selling to replacement demand at a high price may be more profitable than cutting the price in an effort to increase sales.

\footnotetext{
${ }^{9}$ We cannot have $y=0$ as a steady state, since in any stationary equilibrium the monopolist can always guarantee herself a positive profit by charging the price $\underline{v}$ in every period.

${ }^{10}$ Let $h(x)=(1-\mu) t(x)$; then the optimal trajectory of the depreciated stock is $\left\{h^{n}(x)\right\}_{n=0}^{\infty}$. If $h(x)>x$, then the sequence $\left\{h^{n}(x)\right\}$ is increasing, and if $h(x)<x$ then it is decreasing.
} 
Lemma 2 below establishes that there are only three possible steady states: $y_{s}=1, y_{s}=\hat{q}$, and $y_{s}=y^{*}$ (where $y^{*} \in(0, \hat{q})$ will turn out to be uniquely defined). This considerably narrows down our search for stationary equilibria. In particular, if $y_{s}=1$ is the smallest steady state, then we end up with an equilibrium satisfying the Coase Conjecture. If $y_{s}=\hat{q}$ is the smallest steady state, then from the initial state $x=0$ the monopoly steady state is reached. An equilibrium with this property will be referred to as a monopoly equilibrium. In a monopoly equilibrium, depending upon the depreciation rate $\mu$, there may or may not be an additional steady state at $y=1$. However, we will later establish that only one of these two possibilities can occur for any given set of parameters. Finally, if $y_{s}=y^{*}$ is the smallest steady state, we will obtain a reputational equilibrium.

Lemma 2 Consider any stationary equilibrium, and let $S$ denote the associated set of steady states. Then one of the following holds:

i) $S=\{1\}$ (Coase Conjecture equilibrium);

ii) $S=\{\hat{q}\}$ or $S=\{\hat{q}, 1\}$ (Monopoly type equilibrium);

iii) $S=\left\{y^{*}, 1\right\}$, for some $y^{*} \in(0, \hat{q})$ (Reputational equilibrium).

The intuition for Lemma 2 is that in any given stationary equilibrium, the acceptance price at a steady state $y_{s}$ must be equal to $f\left(y_{s}\right)$. Since there cannot exist two distinct steady states with the same acceptance price, and since the number of steps in $f$ equals two, at most two steady states can coexist in equilibrium.

In the analysis of stationary equilibria below, we confine attention to the interesting case where $\underline{v}<\hat{q} \bar{v}{ }^{11}$ When $\underline{v}>\hat{q} \bar{v}$ holds, there is a unique stationary equilibrium, in which the monopolist charges $\underline{v}$ in every period. Indeed, the static monopoly price on the demand curve $f(\cdot)$ then equals $\underline{v}$, so a monopolist with perfect commitment power would charge $\underline{v}$ in every period. Since in any stationary equilibrium consumers will accept the price $\underline{v}$ (see Fudenberg, Levine and Tirole (1985, Lemma 2)), a monopolist without commitment power is then able to earn the commitment profits.

\section{Characterization of Stationary Equilibria}

In this section, we characterize the stationary equilibria corresponding to the three possible configurations of steady states enumerated in Lemma 2. We show that for a given demand curve and

\footnotetext{
${ }^{11}$ The hairline case in which $\underline{v}=\hat{q} \bar{v}$ can be handled as a limit of the case $\underline{v}<\hat{q} \bar{v}$.
} 
fixed parameter values $(\delta, \mu)$ there is at most one equilibrium of each type. We also characterize the range of parameter values $(\delta, \mu)$ for which each type occurs.

\subsection{The Coase Conjecture Equilibrium}

First, we consider equilibria in which $y_{s}=1$ is the unique steady state. In such equilibria, the acceptance price of any buyer type with valuation $\underline{v}$ necessarily equals $\underline{v}{ }^{12}$ Furthermore, because $\hat{q}$ is not a steady state, we have $t(x)=1$ for all $x>(1-\mu) \hat{q} \equiv \bar{x}_{1} \cdot{ }^{13}$ Thus, the fact that $y_{s}=1$ is the unique steady state allows us to completely pin down the associated stationary triplet for $x \in\left(\bar{x}_{1}, 1-\mu\right]$ and $y \in(\hat{q}, 1]$.

*** Place Figure 1 here. Title: The Coase Conjecture Equilibrium ***

We then define a sequence of states $\left\{\bar{x}_{k}\right\}_{k=2}^{m+1}$ such that when the state is $\bar{x}_{k}$ the monopolist is indifferent between selling to $\bar{y}_{k-1}=\frac{\bar{x}_{k-1}}{1-\mu}$ at the price $p_{k-1}$, and to $\bar{y}_{k-2}=\frac{\bar{x}_{k-2}}{1-\mu}$ at the price $p_{k-2}$, where the sequence $\left\{p_{k}\right\}_{k=0}^{m+1}$ is defined such that the high valuation consumer is indifferent between purchasing at $p_{k}$ now and waiting one period to purchase at $p_{k-1}$. This construction is illustrated in Figure 1: for $y \in\left(\bar{y}_{k}, \bar{y}_{k-1}\right]$ we have $P(y)=p_{k-1}$ and $t((1-\mu) y)=\bar{y}_{k-2}$. The arrows in the figure indicate at any state $y$ the direction of movement of the state. As illustrated, in the Coase Conjecture equilibrium the movement is forward, i.e. $t((1-\mu) y)>y$.

Our proof establishes that a necessary and sufficient condition for a Coase Conjecture equilibrium to exist is that the sequence $\left\{\bar{x}_{k}\right\}_{k=1}^{m+1}$ be strictly decreasing and satisfy $\bar{x}_{m+1}<0 \leq \bar{x}_{m}$. We also establish that this condition holds if (and only if) $\mu$ falls below a threshold level $\bar{\mu}$. We therefore have:

Theorem 1 There is at most one Coase Conjecture equilibrium. ${ }^{14}$ This equilibrium exists if and only if $\mu<\bar{\mu}$, for some $0<\bar{\mu}<1$.

\footnotetext{
${ }^{12}$ The intuition for why this is true is as follows. First note that if the acceptance price of type $q \in(\hat{q}, \hat{q}+\varepsilon)$ exceeded $\underline{v}$, then $q$ would expect to make capital gains by purchasing, i.e. $q$ would expect the price to increase next period. Second, since $\hat{q}$ is not a steady state, it must be that type $\hat{q}$ 's acceptance price is below $\bar{v}$, implying that type $\hat{q}$ expects the price to go down next period. But this would mean that the price has to remain constant if the state is $\hat{q}$, which is impossible since $\hat{q}$ is not a steady state.

${ }^{13}$ Since $P(\hat{q})<\bar{v}$, equation (4) implies that $P(\hat{q})>P(t((1-\mu) \hat{q}))$, and so $t((1-\mu) \hat{q})>\hat{q}$. Since $P(q)=\underline{v}$ for $q>\hat{q}$ we have $t((1-\mu) \hat{q})=1$.

${ }^{14}$ More precisely, there exists a unique stationary triplet supporting $y=1$ as the unique steady state. Generically, the outcome path associated with this stationary triplet is unique. Nonuniqueness of the outcome path arises only if $\bar{x}_{m}=0$, in which case the monopolist may randomize between selling to $\bar{y}_{m-1}$ and $\bar{y}_{m-2}$ in the initial period.
} 
Intuitively, the reason why a Coase Conjecture equilibrium does not exist when $\mu$ is large, is that when the state equals $\bar{x}_{1}$, selling to replacement demand $\mu \hat{q}$ at the price $P(\hat{q})=p_{1}=(1-\rho) \bar{v}+\rho \underline{v}$ becomes preferable to fully penetrating the market and selling to replacement demand at the price $\underline{v}$. This is because both the replacement demand $\mu \hat{q}$ and the replacement price $P(\hat{q})$ are then large.

In a Coase Conjecture equilibrium, the seller fully penetrates the market in $m$ periods. We show that $m$ has a finite limit $\hat{m}$ as $z$ approaches zero. Thus, the real time that elapses before the price drops to $\underline{v}$ converges to zero as $z$ approaches zero. Since a high valuation consumer who purchases in the initial period has the option of postponing his purchase decision until time $\hat{m} z$ to purchase at the price $\underline{v}$, the initial price must be close to $\underline{v}$. Hence we conclude:

Corollary 1 In the Coase Conjecture equilibrium, the initial price converges to the lowest buyer valuation $\underline{v}$ as the length of the time period $z$ vanishes.

\subsection{The Monopoly Equilibrium}

Next, we consider equilibria in which $y_{s}=\hat{q}$ is a steady state. In such equilibria the monopolist initially charges the static monopoly price $\bar{v}$ in the first period, selling to all consumers $q \leq \hat{q}$. In subsequent periods, she continues to charge the monopoly price. Hence from then on she serves only replacement demand, which equals $\mu \hat{q}$.

For a monopoly equilibrium to exist, it must be the case that when the state is $x=(1-\mu) \hat{q}$, the monopolist prefers continuing to serve this replacement demand at the monopoly price $P(\hat{q})=\bar{v}$ to penetrating the whole market by charging $P(1)$ and continuing by serving the larger replacement demand at the price $P(1)$ forever, i.e. $\frac{\mu \hat{q} \bar{v}}{1-\delta} \geq(1-(1-\mu) \hat{q}) P(1)+\frac{\delta \mu P(1)}{1-\delta}$. Since $P(1) \geq \underline{v}$, a necessary condition for a monopoly equilibrium to exist is that $\mu \geq \underline{\mu}$, where $\underline{\mu}$ solves the equation $\frac{\mu \hat{q} \bar{v}}{1-\delta}=(1-(1-\mu) \hat{q}) \underline{v}+\frac{\delta \mu \underline{v}}{1-\delta}$. We prove that the condition $\mu \geq \underline{\mu}$ is also sufficient for a monopoly equilibrium to exist. Hence we have:

*** Place Figure 2 here. Title: The Monopoly Equilibrium ***

Theorem 2 There is at most one monopoly equilibrium. This equilibrium exists if and only if $\mu \geq \underline{\mu}$.

The proof of sufficiency is rather subtle. We construct a strictly increasing sequence of states $\left\{\tilde{x}_{k}\right\}_{k=0}^{m+1}$ starting at $\tilde{x}_{0}=(1-\mu) \hat{q}$ and ending at $\tilde{x}_{m+1} \leq 1-\mu$, such that when $k \in\{1, \ldots, m\}$ and the state is $\tilde{x}_{k}$, the monopolist is indifferent between bringing the next period state to $\tilde{x}_{k-1}<\tilde{x}_{k}$ 
and staying at $\tilde{x}_{k}$ forever. This construction is illustrated in Figure 2: for $y \in\left(\tilde{y}_{k-1}, \tilde{y}_{k}\right]$ we have $P(y)=\tilde{p}_{k}$ and $t((1-\mu) y)=\tilde{y}_{k-1}$. The backwards arrows indicate that when the state is $y$ the state moves backward, i.e. $t((1-\mu) y)<y$. Note that for every state $x \in((1-\mu) \hat{q},(1-\mu)]$ it will take at most $m+1$ periods for the state to return to $\tilde{x}_{0}=(1-\mu) \hat{q}$. Upon reaching $\tilde{x}_{0}$, the monopolist then charges the monopoly price forever after.

If $\mu$ is sufficiently large, the monopolist will return to the monopoly steady state from any state above $(1-\mu) \hat{q}$, so $\tilde{x}_{m+1}=1-\mu$. In this case there is a unique steady state, and buyers in the interval $(\hat{q}, 1]$ purchase at a price exceeding their valuation, in order to make capital gains by reselling their good in the second-hand market at some later date. This is illustrated in the left panel of Figure 2. If $\mu$ falls below this threshold, then when the state equals $\tilde{x}_{m+1}$ the monopolist is indifferent between going to $\tilde{x}_{m}$, and fully penetrating the market by charging the price $\underline{v}$, and remain there forever after. In this case $\tilde{x}_{m+1}<1-\mu$ and $y_{s}=1$ is a second steady state. This is illustrated in the right panel of Figure 2.

In a monopoly equilibrium, from any state exceeding $(1-\mu) \hat{q}$ it must take real time for the price to rise to the monopoly price. Letting $\tilde{x}=\lim _{z \rightarrow 0} \tilde{x}_{m(z)+1}$, this means that over the interval $(\hat{q}, \tilde{x}]$, the state must move back slowly to $\hat{q}$. This explains the next Corollary.

Corollary 2 In the limit as the length of the time period $z$ approaches zero, the monopoly equilibrium acceptance price converges to:

$$
P(q)=\left\{\begin{array}{lll}
\bar{v} & \text { for } & q \in[0, \hat{q}] \\
\bar{v}\left(\frac{\hat{q}}{q}\right)^{-\frac{\lambda+r}{\lambda}} & \text { for } & q \in(\hat{q}, \tilde{x}] \\
\underline{v} & \text { for } & q \in(\tilde{x}, 1]
\end{array} .\right.
$$

Furthermore when $x<\hat{q}$ the monopolist sells $(\hat{q}-x)$, when $x>\tilde{x}$ she selects $(1-x)$, and when $x \in(\hat{q}, \tilde{x})$ she selects $\dot{x}=\lambda x\left(1-\frac{v}{\bar{v}}\left(\frac{\hat{q}}{q}\right)^{\frac{\lambda+r}{\lambda}}\right)$.

\subsection{The Reputational Equilibrium}

Finally, we consider equilibria in which $y^{*} \leq \hat{q}$ is a steady state. In such equilibria, starting from the initial state $x=0$ the monopolist charges the price $\bar{v}$ in the every period. She sells to all consumers $y \leq y^{*}$ in the first period, and provides for the replacement demand $\mu y^{*}$ thereafter. In reputational equilibria, the seller's profits therefore fall short of monopoly profits. If the seller were to move the state beyond $y^{*}$ in an attempt to penetrate the market further, she would have to lower her price drastically. This is because for states $y$ beyond $y^{*}$ play occurs according to the Coase 
Conjecture equilibrium. Consumers $y>y^{*}$ therefore expect future prices to be low, and hence are only willing to accept prices close to $\underline{v}$. In effect, by cutting the price, the monopolist "looses her reputation" for pricing high. The reputational equilibrium is illustrated in Figure 3.

However, unlike the equilibria in Ausubel and Deneckere (1989), the equilibria we construct here are stationary. In particular, since depreciation of the stock allows the state to move backwards over time, the monopolist always has the ability to regain her reputation for toughness by keeping sales low over a length of real time sufficient to bring the state back below $y^{*} \cdot{ }^{15}$ Also, unlike in the nonstationary equilibria of Ausubel and Deneckere (1989), the seller's profits are a continuous function of the state.

Continuity implies that when the state is $(1-\mu) y^{*}$, the monopolist's replacement profits $\frac{\mu y^{*} \bar{v}}{1-\delta}$ are equal to the Coase Conjecture profits at $y^{*}$. Since the former are increasing in $y^{*}$ and the latter are decreasing in $y^{*}$, we may conclude that for every value of $\mu$ there is at most one $y^{*} \leq \hat{q}$ such that $y^{*}$ is a steady state. Hence we have:

*** Place Figure 3 here. Title: The Reputational Equilibrium ***

Theorem 3 There is at most one reputational equilibrium. This equilibrium exists if and only if $\underline{\mu}<\mu \leq \bar{\mu}$.

The reason that a reputational equilibrium exist only when a monopoly equilibrium exists is that the profits in the steady state of a reputational equilibrium fall short of the steady state profits in a monopoly equilibrium. Since the temptation to expand sales beyond the steady state (and thereby earn Coase Conjecture profits) is larger in the reputational equilibrium, a reputational equilibrium cannot exist when a monopoly equilibrium fails to exist. From Corollary 1, we conclude:

Corollary 3 Let $y^{*}=\frac{\lambda \underline{v}+r \underline{v}}{\lambda \bar{v}+r \underline{v}}$. Then in the limit as the length of the time period $z$ approaches zero, the reputational equilibrium acceptance price converges to:

$$
P(q)=\left\{\begin{array}{lll}
\bar{v} & \text { for } & q \in\left[0, y^{*}\right] \\
\underline{v} & \text { for } & q \in\left(y^{*}, 1\right] .
\end{array}\right.
$$

\footnotetext{
${ }^{15}$ However, in the reputational equilibrium of our model the monopolist never finds it optimal to regain her reputation once it is lost: once the state moves beyond $y^{*}$ it moves forward until the second steady state $y_{s}=1$ is reached.
} 


\subsection{Coexistence of Stationary Equilibria}

We now turn to the question of when stationary equilibria are unique and when they are not. To settle the issue, we first need an auxiliary result:

Lemma 3 The functions $\bar{\mu}(\delta)$ and $\underline{\mu}(\delta)$ are decreasing, with $\bar{\mu}(0)=\underline{\mu}(0)=\frac{(1-\hat{q}) \underline{v}}{(\bar{v}-\underline{v}) \hat{q}}, \lim _{\delta \rightarrow 1} \underline{\mu}(\delta)=0$ and $\lim _{\delta \rightarrow 1} \bar{\mu}(\delta)>0$.

***Place figure 4 here. Title: Range of $(\delta, \mu)$ where each equilibrium type exists ***

Figure 4 illustrates the situation. At $\delta=0$ a monopoly equilibrium cannot coexist with a Coase Conjecture equilibrium. For any $\delta>0$ the Coase Conjecture equilibrium is the unique equilibrium when $\mu<\underline{\mu}(\delta)$. For $\mu \in[\underline{\mu}(\delta), \bar{\mu}(\delta)]$ all three equilibrium types coexist. Finally, for $\mu>\bar{\mu}(\delta)$ there is only a monopoly equilibrium. The economic force behind this result is that as the depreciation factor increases, staying with monopoly replacement profits becomes more and more attractive relative to further market penetration.

Another way to look at this is that for any given value of $\mu$ a monopoly equilibrium always exists for sufficiently large $\delta$. This is because as long as $\mu>0$, no matter how small, the difference in net present value of replacement profits at $y=\hat{q}$ and at $y=1$ overshadows the one time gain in capturing additional customers. We also see that when the monopolist discounts the future less, a Coase Conjecture equilibrium is less likely to exist. This is because the acceptance price at $\hat{q}$, $P(\hat{q})=(1-\rho) \bar{v}+\rho \underline{v}$ is increasing in $\delta$, so staying at $\hat{q}$ becomes more attractive relative to further market penetration.

Figure 4 also reveals what happens when the length of the time period is allowed to vanish. As $z$ converges to 0 the point $(\delta, \mu)$ then approaches the upper left corner of Figure 4 for all values of $r>0$ and $\lambda<\infty$. Since $\mu=1-e^{-\lambda z}=1-\delta^{\frac{\lambda}{r}}$, the function $\mu(\delta)$ will lie below the graph of $\underline{\mu}(\delta)$ when $\frac{\lambda}{r}$ is small, and above it otherwise. The cut-off value $\lambda_{0}$ below which the Coase equilibrium is the unique equilibrium at $z=0$ is given by $\lambda_{0}=r \frac{(1-\hat{q}) \underline{v}}{v \hat{q}-\underline{v}}$. We summarize the above discussion in:

Corollary 4 (a) Fix any $\mu>\bar{\mu}(1)$. Then for sufficiently low $r$ the monopoly equilibrium is the unique equilibrium.

(b) Let $\lambda_{0}=r \frac{(1-\hat{q}) \underline{v}}{\bar{v} \hat{q}-\underline{v}}$. Then in the limit as the length of the time interval converges to zero, a Coase Conjecture equilibrium exists for all values of $\lambda<\infty$. When $\lambda<\lambda_{0}$ it is the unique equilibrium. When $\lambda>\lambda_{0}$ all three types of equilibria coexist. 
The intuition for why a Coase Conjecture equilibrium always exists when the period length is allowed to vanish, no matter how large the depreciation rate $\lambda$, is as follows. If the monopolist instantly saturates the market with the competitive output, consumers will be willing to pay no more than the competitive price; with such expectations, the monopolist in turn cannot do any better than instantly saturating the market. However, Corollary 4 reveals that in order for Coase's conjecture to hold in a world of imperfect durability, it no longer suffices to let the discount factor between periods converge to one. Unlike in a world of perfect durability, it matters whether this is accomplished by letting the period length vanish, or whether this is accomplished by letting players become infinitely patient. In the first case, replacement demand becomes very small in any given period, whereas in the second case replacement demand can be substantial in a period. In order for the Coase Conjecture to hold in some stationary equilibrium, the monopolist must be able to revise his price frequently enough over any real length of time. Even when this is the case, however, a monopoly equilibrium (and a reputational equilibrium) will still exist when the depreciation rate $\lambda$ is sufficiently high. For example, when $\frac{v}{\overline{\underline{v}}}=.6, \hat{q}=.8$, and $\delta=.95$ then $\underline{\mu}(\delta)=2.9 \%$ and $\bar{\mu}(\delta)=31.8 \%$. Thus when the real interest rate is $5 \%$ per year the monopoly equilibrium will exist if the turnover is less than 34 years, and will be the unique equilibrium if the turnover is less than 3 years. Figure 5 illustrates the equilibrium profits for these parameter values as a function of the depreciation rate $\mu$.

*** Place figure 5 here. Title: Equilibrium profits as a function of $\mu^{* * *}$

\section{The N-step Case}

In this section, we analyze general "neoclassical" demand functions, for which buyers' valuations take on a finite number of values $v_{1}>v_{2}>\ldots>v_{N}>0$. Thus, letting $0=q_{0}<q_{1}<\ldots<q_{N}=1$ we have:

$$
f(q)= \begin{cases}v_{1} & \text { for } q \in\left[0, q_{1}\right] \\ v_{i} & \text { for } q \in\left(q_{i-1}, q_{i}\right], \text { and } i=2, \ldots, N\end{cases}
$$

We discuss below how the techniques used to analyze the two-step demand case can be applied to this larger class, and argue that the qualitative properties we discovered for this case are general.

Lemma 1 continues to hold as stated: in any stationary equilibrium there exists at least one steady state $y_{s}>0$, and $P\left(y_{s}\right)=f\left(y_{s}\right)$. Furthermore, the unique construction of a stationary triplet $\{P, R, t\}$ emanating from a steady state remains valid. For any stationary equilibrium, if 
the acceptance price is below the demand price near the steady state, the expectation of a drop in the future price has to be confirmed by moving the state variable forward. We call this a declining price path. On the other hand, if the acceptance price is above the demand price near the steady state, the expectation of an increase in the future price has to be confirmed by moving the state variable backward. We call this a rising price path. Thus, for generic parameter values only a declining price path can reach a steady state from the left. However, to the right-hand of a steady state, there are two possibilities. Either there is a declining price path that reaches the next steady state, in which case the equilibrium is supported by concerns for reputation, or like in the monopoly equilibrium for the two-step case, there is a rising price path that reaches the steady state from the right. Note that compared to the two-step case, there may now be more than two (but no more than $N$ ) steady states in a stationary equilibrium.

A typical equilibrium therefore has the following structure. There are $J \geq 1$ steady states, $0<y_{1}^{*}<y_{2}^{*}<\ldots<y_{J}^{*}$. To the left of the smallest steady state, the acceptance function lies everywhere (weakly) below the demand function. Letting $h(y)=t((1-\mu) y)$ the monopolist then reaches the steady state $y_{1}^{*}$ in $m_{1}<\infty$ steps, by successively selecting $h(0)<h^{2}(0)<\ldots<$ $h^{m_{1}}(0)=y_{1}^{*}$ (the construction of the stationary equilibrium for states $y \leq y_{1}^{*}$ is described in detail in the proof of Theorem 4) ${ }^{16}$. If $y_{1}^{*}$ is supported by reputational concerns (which is the case whenever $y_{1}^{*} \in\left(q_{k-1}, q_{k}\right)$ for some $\left.k\right)$, then whenever the initial state $x=(1-\mu) y$ lies in the interval $\left((1-\mu) y_{1}^{*},(1-\mu) y_{2}^{*}\right]$ the monopolist reaches the steady state $y_{2}^{*}$ in $m \leq m_{2}<\infty$ steps, by successively selecting $h(y)<h^{2}(y)<\ldots<h^{m}(y)=y_{2}^{*}$. Furthermore, at $x=(1-\mu) y_{1}^{*}$ the monopolist is indifferent between serving replacement demand at $y_{1}^{*}$ forever, and selling to $h\left(y_{1}^{*}+\varepsilon\right)$ and continuing optimally thereafter. If $y_{1}^{*}=q_{k}$ for some $k<N$ then there exists $\widetilde{x} \in\left[(1-\mu) y_{1}^{*},(1-\mu) y_{2}^{*}\right)$ such that when the initial state $x=(1-\mu) y \in\left((1-\mu) y_{1}^{*}, \widetilde{x}\right]$ the monopolist reaches the steady state $y_{1}^{*}$ in $m_{2}^{\prime}<\infty$ steps, by selling to $h(y)>h^{2}(y)>\ldots>h^{m_{2}^{\prime}}(y)=y_{1}^{*}$, so market penetration decreases over time (the construction of the stationary equilibrium for states $y \in\left(y_{1}^{*}, \widetilde{x}\right]$ is described in detail in the proof of Theorem 4). ${ }^{17}$ When $x \in\left(\widetilde{x},(1-\mu) y_{2}^{*}\right]$ the monopolist reaches $y_{2}^{*}$ in a finite number of steps. For any $j$ s.t. $2 \leq j<J$ and initial states in $\left((1-\mu) y_{j}^{*},(1-\mu) y_{j+1}^{*}\right]$ the equilibrium between $\left[(1-\mu) y_{j}^{*},(1-\mu) y_{j+1}^{*}\right)$ can again have one of two possible structures, depending upon whether or not $y_{j}^{*}$ is a discontinuity point of $f$. Finally, for initial states $x \in\left((1-\mu) y_{J}^{*}, 1-\mu\right]$ the monopolist returns to the steady state $y_{J}^{*}$ in a finite number

\footnotetext{
${ }^{16}$ See the definition of the sequence $\left\{\bar{x}_{k}^{i}\right\}$, where $\bar{x}_{0}^{i}=(1-\mu) y_{1}^{*}$.

${ }^{17}$ See the definition of the sequence $\left\{\widetilde{x}_{k}^{i}\right\}$, where $\widetilde{x}_{0}^{i}=(1-\mu) y_{1}^{*}$.
} 
of steps.

In the two-step case, we established the existence of a stationary equilibrium in an indirect way, by characterizing all values of the parameters $(\delta, \mu)$ for which each type of equilibrium exists. Because the number of possible equilibria is at least of order $2^{N}$, enumerating all possible equilibria for the $N$-step case quickly becomes unwieldy, so instead we construct a stationary equilibrium for any fixed set of parameter values. The equilibrium is constructed so that its acceptance function dominates the acceptance function in any other possible stationary equilibrium.

Theorem 4 Let $f$ be any demand function taking on a finite number of values. Then for any $0 \leq \delta<1$ and $0 \leq \mu<1$ there exists at least one stationary equilibrium.

From here on suppose that there is a unique monopoly quantity $q^{*}$ on the demand curve $f(\cdot)$ (Note that this will generically be the case). We define a stationary equilibrium to be a Coase Conjecture equilibrium if the smallest steady state $y_{1}^{*}=1$. As in the two-type case, such an equilibrium is necessarily unique. We say that a stationary equilibrium is of the monopoly type if $y_{1}^{*}=q^{*}$. In a monopoly type equilibrium, starting from the initial state $x=0$, the steady state $q^{*}$ is always reached in a single step. However, unlike in the case $N=2$ several qualitatively distinct monopoly type equilibria may now coexist for a given set of parameter values (these equilibria thus have different acceptance functions over the interval $\left.\left(q^{*}, 1\right]\right)$. Finally, we define a stationary equilibrium to be of the reputational type if $y_{1}^{*}$ is not a discontinuity point of $f(\cdot)$.

Our next result shows that, just like in the two-step case, when the good is sufficiently durable only a Coase Conjecture equilibrium can exist, and when the good is sufficiently perishable only monopoly type equilibria can exist. Furthermore, reputational equilibria with a steady state below the monopoly quantity always exist for intermediate values of the parameter $\mu$. Importantly, as in the two-type case, if monopoly type equilibria do not exist the equilibrium outcome will never produces lower surplus than static monopoly surplus.

Showing that only a Coase Conjecture equilibrium can exist when durability is sufficiently high is straightforward, as all we need to rule out is the possibility of a rising price path in a right neighborhood of any potential steady state. For this, it suffices to check that a deviation to full market saturation always pays. However, showing that no equilibria other than the monopoly type equilibria exist when durability is sufficiently low is complicated, for we need to establish that any declining price path reaching a steady state beyond the monopoly quantity $q^{*}$ cannot emanate from a state below $(1-\mu) q^{*}$. To establish the existence of reputational equilibria with $y_{1}^{*}<q^{*}$, we first 
show there exists a value of the depreciation rate $\mu=\mu_{L}$ such that at $\mu_{L}$ there is a monopoly type equilibrium in which $h(y)>y$ for all $y \in\left(q^{*}, y_{2}^{*}\right)$. We then show that this "borderline" reputational equilibrium becomes a reputational equilibrium when $\mu$ is perturbed upward.

Theorem 5 (i) For every $\delta<1$ there exists $\underline{\mu}(\delta)>0$ such that for $\mu \in[0, \underline{\mu}(\delta))$ the Coase Conjecture equilibrium is the unique stationary equilibrium.

(ii) For every $\delta<1$ there exists $\bar{\mu}(\delta)<1$ such that for all $\mu \in(\bar{\mu}(\delta), 1]$, every stationary equilibrium is of the monopoly type.

(iii) For every $\delta<1$ there exists $\left(\mu_{L}(\delta), \mu_{H}(\delta)\right) \subset(\underline{\mu}(\delta), \bar{\mu}(\delta))$ such that for all $\mu \in\left(\mu_{L}(\delta), \mu_{H}(\delta)\right)$ there is a reputational equilibrium whose smallest steady state falls below the monopoly quantity $q^{*}$.

(iv) If the monopoly quantity $q^{*}$ cannot be a steady state, then no $q<q^{*}$ can be a steady state either.

\section{Endogenous Choice of Durability}

Suppose now that the monopolist has the ability to choose the durability of the product she sells. For simplicity let demand be given by (2), and let production occur at a constant marginal cost $c(\lambda)>0$, satisfying $r c(0)<b$. We assume that the rental cost associated with the depreciation rate $\lambda,(r+\lambda) c(\lambda)$, is strictly increasing in $\lambda .{ }^{18},{ }^{19}$ Since the flow benefit from the services of a unit of the durable good is constant, the social optimum requires $\lambda=0$, and since $r c(0)<b$ both consumer types are served in the social optimum.

As far as stationary equilibria are concerned, we will focus on the limiting case where $z \rightarrow 0$. A condition analogous to Corollary 4 (ii) then holds: there exists a unique value $\lambda_{0}$ such that the Coase conjecture equilibrium is the unique equilibrium whenever $\lambda<\lambda_{0}$, and such that all three types of equilibria coexist whenever $\lambda \geq \lambda_{0} \cdot{ }^{20}$

First, let us consider the incentive to distort the level of durability in the Coase Conjecture equilibrium. To guarantee that this equilibrium is necessarily played, we assume that the user cost

\footnotetext{
${ }^{18}$ This allows $c(\lambda)$ to be decreasing in $\lambda$, but at a rate sufficiently low that the user cost is minimized at $\lambda=0$.

${ }^{19}$ The monotonicity condition can be relaxed to the requirement that $(r+\lambda) c(\lambda)$ is uniquely minimized at $\lambda=0$. In Proposition 1 we then need to require $\inf _{\lambda \geq \lambda_{0}}(r+\lambda) c(\lambda)>\bar{c}$, and in Proposition 2 we conclude that the monopolist selects $\lambda \geq \lambda_{0}$.

${ }^{20}$ Specifically, $\lambda_{0}$ is the unique solution to

$$
\lambda=r \frac{(b-(r+\lambda) c(\lambda))(1-\hat{q})}{\hat{q}(a-(r+\lambda) c(\lambda))-(b-(r+\lambda) c(\lambda))} .
$$
}


$\left(r+\lambda_{0}\right) c\left(\lambda_{0}\right)$ is sufficiently large that the monopolist will never select a depreciation rate $\lambda \geq \lambda_{0}$. Specifically, we require that $\left(r+\lambda_{0}\right) c\left(\lambda_{0}\right)>\bar{c} \equiv \frac{a \hat{q}-b+r c(0)}{\hat{q}}$ for all $\lambda \geq \lambda_{0} \cdot{ }^{21}$

Proposition 1 Suppose that $\left(r+\lambda_{0}\right) c\left(\lambda_{0}\right)>\bar{c}$. Then in the limit as $z \rightarrow 0$ the monopolist selects the socially optimal level of durability.

Bulow (1986) argued that a monopoly seller of an infinitely durable good has an incentive to build in obsolescence. Indeed, the Coase Conjecture undermines the monopolist's implicit commitment power; reducing durability from the efficient level allows her to regain some of this commitment power. But Bulow failed to take this argument to its logical conclusion: when the length of time period becomes vanishingly small, according to Proposition 1 this distortion must disappear. The reason is as follows: when $z \rightarrow 0$, the Coase Conjecture forces the benefit the monopolist receives from any given reduction in durability to zero. Meanwhile, the monopolist's cost of providing the equilibrium stream of services (which, by the Coase Conjecture, is fixed at the competitive level) strictly increases.

Nevertheless, our results imply that there is scope for the monopolist to distort the level of durability below the socially optimal level when $\left(r+\lambda_{0}\right) c\left(\lambda_{0}\right)<\bar{c}$ :

Proposition 2 Suppose that $\left(r+\lambda_{0}\right) c\left(\lambda_{0}\right)<\bar{c}$, and that the monopoly equilibrium is played for all $\lambda \geq \lambda_{0}$. Then in the limit as $z \rightarrow 0$ the monopolist selects $\lambda=\lambda_{0}$.

The impetus behind this "planned obsolescence" is quite different from Bulow's. In the Coase Conjecture equilibrium, when $z \rightarrow 0$ the durability of the good no longer affects the monopolist's ability to exercise her monopoly power. In contrast, by selecting $\lambda>\lambda_{0}$ the monopolist can affect her ability to exercise monopoly power, even as $z \rightarrow 0$. Lowering durability allows the monopolist to credibly commit to a higher steady state price, leading to a distortion in the choice of durability.

Let us now briefly address the incentive to distort durability when $z>0$. The major difference with the limiting case is that now the monopolist is able to guarantee that the monopoly equilibrium is played, by selecting a level of durability equal to $\bar{\mu}$. That such a strategy can be profitable is illustrated in Figure 5. More generally, whenever players are sufficiently patient (i.e. for sufficiently small $r$ ), selecting $\mu=\bar{\mu}$ will dominate selecting any $\mu$ that leads to a Coase Conjecture equilibrium.

\footnotetext{
${ }^{21}$ Under this condition, the monopolist prefers the Coase profits at $\lambda=0$ to the monopoly profits at $\lambda=\lambda_{0}$. More precisely, $b-r c(0)>\left(a-\left(r+\lambda_{0}\right) c\left(\lambda_{0}\right)\right) \hat{q}$.
} 


\section{$7 \quad$ Related Literature}

Sobel (1991) considers a market for an infinitely durable good in which demand grows over time. Thus like in our model, the monopolists' demand never dries up. However, if the monopolist were to keep on charging the static monopoly price forever, she would accumulate a backlog of low valuation consumers that grows as time passes on. This backlog eventually becomes so large that it becomes attractive to lower the price. As a consequence, contrary to the depreciation case, all stationary equilibria of Sobel's model satisfy the Coase Conjecture.

Bond and Samuelson (1984) study a market with linear demand for an exponentially depreciating durable good. Using a procedure similar to Stokey (1981) and Sobel and Takahashi (1983), they construct a linear-quadratic equilibrium, and show that it satisfies the Coase Conjecture for all finite depreciation rates. Bond and Samuelson's analysis fails to uncover other stationary equilibria for their model, and therefore suggests that the limiting outcome must be the competitive outcome. Our paper shows that this is not the case. ${ }^{22}$

Bond and Samuelson (1987) revisit the linear demand example, extending Ausubel and Deneckere's (1989) construction of reputational equilibria to markets for products with limited durability. These equilibria are qualitatively very different from the reputational equilibria discovered in the present paper. All of our equilibria are stationary, while Bond and Samuelson's equilibria are nonstationary. This distinction is important, for several reasons. First, nonstationary equilibria rely on punishments for deviating from a pre-specified outcome path. In contrast, in our reputational equilibria the seller's profits are (Lipschitz) continuous in the state. Thus if the seller deviates from equilibrium by expanding sales beyond the steady state level, she receives no punishment. Secondly, stationary equilibria embody the Markovian restriction that players only pay attention to the portion of the history that is payoff relevant, which many authors regard as desirable. ${ }^{23}$ Finally, nonstationary equilibria permit virtually any price path to arise in equilibrium when the length of the time period is sufficiently small, and hence have little predictive power. In contrast, the requirement of stationarity significantly reduces the size of the equilibrium set. To

\footnotetext{
${ }^{22}$ For smooth demand curves, Theorem 5 (a) generalizes to the requirement that all stationary equilibria must be close to the monopoly equilibrium when $\mu$ is sufficiently large. Bond and Samuelson's equilibrium satisfies this property. However, unlike in our monopoly equilibrium, this equilibrium approaches the competitive outcome when the time between offers is allowed to vanish, no matter how large the depreciation rate.

${ }^{23}$ The Markovian restriction is implied by Harsanyi and Selten's (1988) principle of subgame consistency, which holds that behaviour in any subgame should only depend upon the structure of that subgame.
} 
see this, note that for the case of a "gap" analyzed in the present paper, the seller's profit in any stationary equilibrium is bounded below by the Coase Conjecture payoff, which is no lower than $v_{N}$. In contrast, the worst non-stationary payoff converges to zero as the length of the time period shrinks to zero. ${ }^{24}$

The paper that is perhaps most closely related to the present work is Karp (1996). Karp considers a continuous time model, and shows that for any positive depreciation rate there exists a continuum of stationary equilibria, only one of which satisfies the Coase Conjecture. Our models are similar, and our results are complementary to Karp's. However, there are important differences. First, we analyze a discrete time model, and this allows us to uncover interesting results that are unobtainable in Karp's continuous time framework. For example, in our model, when players become arbitrarily patient (i.e. the discount rate $r$ converges to zero) and the depreciation factor is sufficiently large, the monopoly outcome is the unique stationary equilibrium outcome. In contrast, Karp's model predicts that any stock below the competitive stock can be a steady state. Secondly, Karp's analysis is limited to strictly decreasing continuous demand functions, and hence explicitly rules out discontinuities and flat sections in the monopolists's demand function. Our paper shows how these can be handled. Thirdly, and most importantly, it is well-known that the continuous time method can introduce spurious equilibria. For example, in the durable goods monopoly model with learning-by-doing analyzed by Deneckere and Liang (2006) the continuous time model has a continuum of qualitatively distinct equilibria, only one of which is the limit of the unique stationary equilibrium of the corresponding discrete time model. This raises the real possibility that many of the equilibria uncovered by Karp (1996) are an artifact of the continuous time approach. Indeed, our results imply that most of Karp's "Strong Markov Perfect Equilibria" are fragile to small perturbations in the model. More precisely, there is a continuum of qualitatively distinct SMPE emanating from any steady state; we show that only one of them can be the limit of discrete time equilibria of arbitrarily fine step function approximations to the monopolist's demand function. Thus, we provide a method for determining which continuous time equilibria are reasonable. Finally, our results reveal that Karp's analysis failed to uncover an important class of equilibria, the class of "stationary reputational equilibria."

\footnotetext{
${ }^{24} \mathrm{As}$ an additional illustration of this cutting power, note that the two-type model has at most three stationary equilibria, but a continuum of nonstationary equilibria (when the length of the time period is sufficiently small).
} 


\section{Conclusion}

In this paper, we have developed a discrete-time model of a monopolist selling a new imperfectly durable good. We characterized its stationary equilibria as a function of three parameters, the common discount rate of the seller and the consumers, the depreciation rate of the good, and the length of the time period between successive price changes. We have shown that for any given positive period length, there is a unique equilibrium outcome when the good is either sufficiently perishable or sufficiently durable. In the former case, the only equilibrium outcome is the monopoly outcome, whereas in the latter case the unique outcome is the Coase Conjecture outcome. For intermediate values of the depreciation rate, equilibria with steady states ranging from the competitive output to the monopoly output, and even below the monopoly output, can coexist. These results persist even if players become arbitrarily patient; however the range of depreciation rates for which only a Coase Conjecture equilibrium exists shrinks to zero. In the limit, a monopoly equilibrium always exists, while a Coase Conjecture equilibrium exists only if the depreciation rate is sufficiently small. Taken together, these results show that the equilibrium outcome set varies continuously from the competitive outcome to the monopoly outcome as the depreciation rate varies from zero to infinity. Furthermore, when players are very patient, the monopoly outcome can be obtained unless the good has almost infinite durability.

To keep our model tractable, and facilitate comparison with the existing literature, we stuck with a traditional Wicksellian formulation of the durable goods market. In particular, we assumed that new and used durables are perfect substitutes and that there exists a perfect second-hand market. While the second-hand market is never active along the equilibrium outcome path of a stationary equilibrium, it is active following off-equilibrium behavior of the monopolist. Thus the operation of the second-hand market plays an important role in sustaining equilibrium behavior. For this reason, it would be interesting to extend our analysis to cases where the second-hand market operates imperfectly, either because of adverse selection (as in Hendel and Lizzeri (1999a), Janssen and Roy (2002), Johnson and Waldman (2003), House and Leahy (2004), and Hendel, Lizzeri and Siniscalchi (2005)), or because of transaction costs (Konishi and Sandfort (2002), Stolyarov (2002)). Relaxing the assumption of perfect substitutability between new and used durables (as in Rust (1985), Waldman (1996), or Hendel and Lizzeri (1999b)) might also be a fruitful avenue of research. The intuition put forth in our paper strongly suggests that our results are robust to these variations, but a formal analysis must await future work. 


\section{Appendix}

\section{Proof of Lemma 1:}

First, if $y_{s}$ is the stock after trade in a steady state, then $P\left(y_{s}\right)=f\left(y_{s}\right)$. The reason is that in the steady state we have $t\left((1-\mu) y_{s}\right)=y_{s}$. Hence, the consumer's arbitrage equation $f\left(y_{s}\right)-P\left(y_{s}\right)=\rho\left[f\left(y_{s}\right)-P\left(t\left((1-\mu) y_{s}\right)\right)\right]$ implies $P\left(y_{s}\right)=f\left(y_{s}\right)$.

To prove that a steady state must exist, we first show that if $P$ and $f$ cross, then there always is a steady state. Then we establish that $P$ and $f$ necessarily cross.

We claim that if $S=\{q: P(q)=f(q)\}$ is non-empty then $q^{\prime}=\max S$ is a steady state. To see this, observe that $q^{\prime}$ is the maximum state to have acceptance price $P\left(q^{\prime}\right)$. Indeed, if there existed $q^{\prime \prime}>q^{\prime}$ with $P\left(q^{\prime \prime}\right)=P\left(q^{\prime}\right)$, then from the definition of $q^{\prime}$ we must have $f\left(q^{\prime \prime}\right)<f\left(q^{\prime}\right)$. Furthermore, since $t(\cdot)$ is non-decreasing, and since $P(\cdot)$ is non-increasing, we have $P\left(t\left((1-\mu) q^{\prime \prime}\right)\right) \leq$ $P\left(t\left((1-\mu) q^{\prime}\right)\right)$. This implies the contradiction $P\left(q^{\prime \prime}\right)=(1-\rho) f\left(q^{\prime \prime}\right)+\rho P\left(t\left((1-\mu) q^{\prime \prime}\right)\right)<(1-$

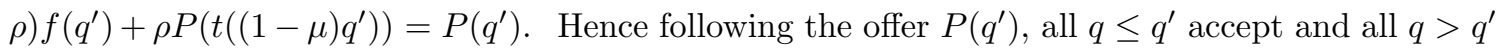
reject. Now from $P\left(q^{\prime}\right)=(1-\rho) f\left(q^{\prime}\right)+\rho P\left(t\left((1-\mu) q^{\prime}\right)\right)$ and $P\left(q^{\prime}\right)=f\left(q^{\prime}\right)$ we have $P\left(t\left((1-\mu) q^{\prime}\right)\right)$ $=P\left(q^{\prime}\right)$. Thus when the state before trade is $(1-\mu) q^{\prime}$ the monopolist's price $P\left(t\left((1-\mu) q^{\prime}\right)\right)$ $=P\left(q^{\prime}\right)$ leads to a state after trade equal to $q^{\prime}$, i.e. $t\left((1-\mu) q^{\prime}\right)=q^{\prime}$.

Suppose now that there is a stationary equilibrium which does not have any steady state. We claim that this implies $P(q)<\bar{v}$ for $q \in[0, \hat{q}]$ and $P(q)>\underline{v}$ for $q \in(\hat{q}, 1]$. To see this, note that since there is no steady state, it follows from the previous paragraph that the set $S$ is empty, i.e. $P(q) \neq \bar{v}$ for any $q \in[0, \hat{q}]$ and $P(q) \neq \underline{v}$ for any $q \in(\hat{q}, 1]$. An argument similar to Fudenberg, Levine and Tirole (1985, Lemma 2) establishes that $P(q) \geq \underline{v}$ for all $q \in[0,1]$. Hence we necessarily have $P(q)>\underline{v}$ for all $q \in(\hat{q}, 1]$. Furthermore, we cannot have $P(q)>\bar{v}$ for some $q \in[0, \hat{q}]$. Otherwise, since $P(\cdot)$ is non-increasing, we would have $P(0)>\bar{v}$. But then $P(0)=(1-\rho) \bar{v}+\rho P(t(0))$ implies $P(t(0))>P(0)$. This is a contradiction, as $t(0) \geq 0$ and $P(\cdot)$ is a non-increasing function.

Next, we show that $P(q)<\bar{v}$ for $q \in[0, \hat{q}]$ and $P(q)>\underline{v}$ for $q \in(\hat{q}, 1]$ imply that the total stock is increasing for $q \in[0, \hat{q}]$ and decreasing for $q \in(\hat{q}, 1]$, and that this yields a contradiction.

By the consumer's arbitrage equation, we have $\bar{v}-P(q)=\rho[\bar{v}-P(t((1-\mu) q)]$ for all $q \in[0, \hat{q}]$. Since $\rho \in(0,1)$ for all $z>0$ and $\bar{v}-P(q)>0$, we have $\bar{v}-P(q)<\bar{v}-P(t(1-\mu) q)$ which implies $P(t((1-\mu) q))<P(q)$ for all $q \in[0, \hat{q}]$. Since $P(\cdot)$ is decreasing, we have $t((1-\mu) q)>q$ for all $q \in[0, \hat{q}]$.

A similar argument also establishes that $t((1-\mu)(\hat{q}+\epsilon))<\hat{q}+\epsilon$ for all $\epsilon \in(0,1-\hat{q}]$. Hence, 
$\lim _{\epsilon \rightarrow 0} t((1-\mu)(\hat{q}+\epsilon)) \leq \hat{q}<t((1-\mu) \hat{q})$. Since $T(\cdot)$ is upper hemi-continuous, $\lim _{\epsilon \rightarrow 0} t((1-\mu)(\hat{q}+$ $\epsilon)) \in T((1-\mu) \hat{q})$. This contradicts the definition of $t(\cdot)=\min T(\cdot)$ Q.E.D.

Lemma 4 If $f(q)=f\left(q^{\prime}\right)$ and $P(q)=P\left(q^{\prime}\right)$ for some $q<q^{\prime}$ then $q$ cannot be a steady state.

Proof : If $q$ were a steady state, then when the state after depreciation is $(1-\mu) q$ the monopolist will charge $P(q)$. All buyers in $\left((1-\mu) q, q^{\prime}\right]$ will accept this, contradicting that $t((1-\mu) q)=q$. Q.E.D.

\section{Proof of Lemma 2:}

First, we show that $y \in(\hat{q}, 1)$ cannot be a steady state. Suppose not; then Lemma 1 implies that $P(y)=\underline{v}$. Since $P(\cdot)$ is a decreasing function, we have $P(q) \leq \underline{v}$ for $q \geq y$. Similar to Fudenberg, Levine, and Tirole (1985), we have $P(q) \geq \underline{v}$ for all $q \in[0,1]$. Hence, $P(q)=\underline{v}$ for all $q \in[y, 1]$. Lemma 4 then shows that $y$ cannot be a steady state.

To prove (ii), suppose that $\hat{q}$ is a steady state so that $P(\hat{q})=\bar{v}$. Then since $P(\cdot)$ is decreasing, and since (as shown in the proof of Lemma 1) $P(y) \leq \bar{v}$ for $y \leq \hat{q}$, we have $P(y)=\bar{v}$ for all $y \in[0, \hat{q}]$. Hence Lemma 4 shows that $y<\hat{q}$ cannot be a steady state. We conclude that the only possible steady state other than $\hat{q}$ is 1 .

To prove (iii) suppose that $0<y^{*}<\hat{q}$ is a steady state. Then we must have $P(y)=\bar{v}$ for all $y \in\left[0, y^{*}\right]$, so Lemma 4 implies that no $y<y^{*}$ can be a steady state, and that $P(q)<\bar{v}$ for $q \in\left(y^{*}, \hat{q}\right]$ (otherwise $y^{*}$ could not be a steady state). Thus by Lemma 1 no $y \in\left(y^{*}, \hat{q}\right]$ can be a steady state, leaving $y=1$ as the only other possible steady state. Suppose $y=1$ were not a steady state, so $P(1)>\underline{v}$. This would imply $P(q)>\underline{v}$ for all $q \in(\hat{q}, 1]$. We can then use the argument at the end of the proof of Lemma 1 to obtain a contradiction.

To prove (i), note that if there is no steady state in $[0, \hat{q}]$, then by the first paragraph $y=1$ is the only possible steady state. It then follows from Lemma 1 that $y=1$ must be a steady state. Q.E.D.

\section{Proof of Theorem 4:}

For all $i=1, \ldots, N-1$, analogously to the two-step case, given $q_{i}$ as a steady state construct a sequence $\left\{\tilde{x}_{k}^{i}\right\}_{k=0}^{\infty}$ to the right of $q_{i}$ as follows. Let $\tilde{x}_{0}^{i}=(1-\mu) q_{i}$ and let $\tilde{P}^{i}(q)=(1-\rho) f(q)+$ $\rho f\left(q_{i}\right)$ for $q \geq q_{i}$. Given $\tilde{P}^{i}(\cdot)$, let $\tilde{x}_{1}^{i}$ be the highest state such that the seller prefers selecting $y=q_{i}$ to selecting $y \in\left(q_{i}, \tilde{y}_{1}^{i}\right]$. For $k \geq 2$ let $\tilde{t}^{i}(q)$ be the seller's optimal choice over $\left(\tilde{y}_{k-2}^{i}, \tilde{y}_{k-1}^{i}\right]$ and redefine $\tilde{P}^{i}(q)=(1-\rho) f(q)+\rho f\left(\tilde{t}^{i}(q)\right)$ for $q \geq \tilde{y}_{k-1}^{i}$. Finally, let $\tilde{x}_{k}^{i}$ be the highest state 
such that the seller prefers selecting $y \in\left(\tilde{y}_{k-2}^{i}, \tilde{y}_{k-1}^{i}\right]$ to selecting $y \in\left(\tilde{y}_{k-1}^{i}, \tilde{y}_{k}^{i}\right]$. Let $\tilde{R}^{i}(q)$ be the seller's payoff function associated with $\tilde{P}^{i}(q)$.

Also analogously to the two-step case, given $q_{i}$ as a steady state construct a sequence $\left\{\bar{x}_{k}^{i}\right\}$ to the left of $q_{i}$ as follows. Let $\bar{x}_{0}^{i}=(1-\mu) q_{i}$ and let $\bar{P}^{i}(q)=(1-\rho) f(q)+\rho f\left(q_{i}\right)$ for $q \leq q_{i}$. Given $\bar{P}^{i}(\cdot)$, let $\bar{x}_{1}^{i}$ be the smallest state such that the seller prefers selecting $y=q_{i}$ to selecting $y \in\left(\bar{y}_{1}^{i}, q_{i-1}\right]$. For $k \geq 2$ let $\bar{t}^{i}(q)$ be the seller's optimal choice over $\left(\bar{y}_{k-1}^{i}, \bar{y}_{k-2}^{i}\right]$ and redefine $\bar{P}^{i}(q)=(1-\rho) f(q)+\rho f\left(\bar{t}^{i}(q)\right)$ for $q<\bar{y}_{k-1}^{i}$. Finally, let $\bar{x}_{k}^{i}$ be the smallest state such that the seller prefers selecting $y \in\left(\bar{y}_{k-1}^{i}, \bar{y}_{k-2}^{i}\right]$ to selecting $y \in\left(\bar{y}_{k}^{i}, \bar{y}_{k-1}^{i}\right]$. Let $m^{i}$ be the largest value of $k$ such that $0 \leq \bar{x}_{j}^{i}<\bar{x}_{j-1}^{i}$ for all $j \leq k$, and let $\bar{R}^{i}(q)$ be the seller's payoff function associated with $\bar{P}^{i}(q)$.

Let $A_{0}=\left\{i \mid \lim _{k \rightarrow \infty} \tilde{x}_{k}^{i} \geq 1-\mu\right\}$. If $A_{0}=\phi$, let $q_{i_{0}}=1$. Otherwise, let $i_{0}=\min A_{0}$. Then define $P(q)=\tilde{P}^{i_{0}}(q)$ for $q>q_{i_{0}}$. Also let $R(q)$ and $t(q)$ be the equilibrium value function and policy function associated with $P(q)$.

(P) Now we will construct $P(q)$ for $q \leq q_{i_{0}}$. Define $i_{1}$ such that $\lim _{k \rightarrow \infty} \tilde{x}_{k}^{i_{1}} \geq \lim _{k \rightarrow \infty} \tilde{x}_{k}^{i}$ for all $i<i_{0}$. Note that $\lim _{k \rightarrow \infty} \tilde{x}_{k}^{i_{1}}>(1-\mu) q_{i_{0}-1}$ because $\lim _{k \rightarrow \infty} \tilde{x}_{k}^{i_{0}-1}>(1-\mu) q_{i_{0}-1}$. If $\bar{R}^{i_{0}}\left((1-\mu) q_{i_{0}-1}\right)<\tilde{R}^{i_{1}}\left((1-\mu) q_{i_{0}-1}\right)$, let $q^{\prime}$ be such that $\bar{R}^{i_{0}}\left((1-\mu) q^{\prime}\right)=\tilde{R}^{i_{1}}\left((1-\mu) q^{\prime}\right)$, and set $P(q)=\bar{P}^{i_{0}}(q)$ for $q \in\left(q^{\prime}, q_{i_{0}}\right]$ and $P(q)=\tilde{P}^{i_{1}}(q)$ for $q \in\left(q_{i_{1}}, q^{\prime}\right]$. Now return to (P) with $i_{1}$ taking the role of $i_{0}$. (P') If $\bar{R}^{i_{0}}\left((1-\mu) q_{i_{0}-1}\right) \geq \tilde{R}^{i_{1}}\left((1-\mu) q_{i_{0}-1}\right)$ a proof similar to the one showing $\underline{\mu}<\bar{\mu}$ in the two-step case yields $\bar{x}_{m^{i_{0}}} \leq q_{i_{0}-2}$. Hence, $\bar{P}^{i_{0}}(q)$ exists for $q \in\left(q_{i_{0}-2}, q_{i_{0}-1}\right]$. Define $i_{2}$ such that $\lim _{k \rightarrow \infty} \tilde{x}_{k}^{i_{2}} \geq \lim _{k \rightarrow \infty} \tilde{x}_{k}^{i}$ for all $i<i_{0}-1$. If $\bar{R}^{i_{0}-1}\left((1-\mu) q_{i_{0}-2}\right)<\tilde{R}^{i_{2}}\left((1-\mu) q_{i_{0}-2}\right)$, let $q^{\prime}$ be such that $\bar{R}^{i_{0}-1}\left((1-\mu) q^{\prime}\right)=\tilde{R}^{i_{2}}\left((1-\mu) q^{\prime}\right)$, and set $P(q)=\bar{P}^{i_{0}-1}(q)$ for $q \in\left(q^{\prime}, q_{i_{0}-1}\right]$ and $P(q)=\tilde{P}^{i_{2}}(q)$ for $q \in\left(q_{i_{2}}, q^{\prime}\right]$. Now return to (P) with $i_{2}$ taking the role of $i_{0}$. If $\bar{R}^{i_{0}-1}\left((1-\mu) q_{i_{0}-2}\right) \geq \tilde{R}^{i_{2}}\left((1-\mu) q_{i_{0}-2}\right)$ then return to (P') with $i_{2}$ taking the role of $i_{1}$ and $q_{i_{0}-2}$ taking the role of $q_{i_{0}-1}$.

Q.E.D. 


\section{References}

Ausubel, L. and R. Deneckere (1989), "Reputation in Bargaining and Durable Goods Monopoly," Econometrica, 57, 511-531.

Ausubel, L. and R. Deneckere (1993), "A Generalized Theorem of the Maximum," Economic Theory, 3, 99-107.

Bond, E. and L. Samuelson (1984), "Durable Good Monopolies with Rational Expectations and Replacement Sales," RAND Journal of Economics, 15, 336-345.

Bond, E. and L. Samuelson (1987), "The Coase Conjecture Need Not Hold for Durable Good Monopolies with Depreciation," Economics Letters, 24, 93-97.

Bulow, J. (1986), "An Economic Theory of Planned Obsolescence," The Quarterly Journal of Economics, 101 729-749.

Butz, D. (1990), "Durable-Good Monopoly and Best-Price Provisions," American Economic Review, 80(5), 1062-76.

Chevalier, J. and A. Goolsbee (2005), "Are Durable Goods Consumers Forward Looking? Evidence from College Textbooks," mimeo, Yale University.

Coase, R. (1972), "Durability and Monopoly," Journal of Law and Economics, 15, 143-149.

Deneckere, R. and M. Liang (2005), "Does a Second-Hand Market Limit a Durable Goods Monopolist's Market Power?," mimeo, University of Wisconsin-Madison.

Deneckere, R. and M. Liang (2006), "Bargaining with Interdependent Values," Econometrica, 74(5), 1309-1364.

Fudenberg, D. and J. Tirole (1983): "Sequential Bargaining with Incomplete Information," Review of Economic Studies, 50, 221-247.

Fudenberg, D., D. Levine, and J. Tirole (1985), "Infinite Horizon Models of Bargaining with OneSided Incomplete Information," in Game Theoretic Models of Bargaining, A. Roth (Ed.), Cambridge: Cambridge University Press.

Gul, F., H. Sonnenschein, and R. Wilson (1986), "Foundations of Dynamic Monopoly and the Coase Conjecture," Journal of Economic Theory, 39, 155-190. 
Harsanyi, J. and R. Selten (1988), A General Theory of Equilibrium Selection in Games, MIT Press, Cambridge, Massachusetts.

Hart, O. (1989), "Bargaining and Strikes," Quarterly Journal of Economics, 104, 25-43.

Hendel, I. and A. Lizzeri (1999a), "Adverse Selection in Durable Goods Markets," American Economic Review, 89(5), 1097-1115.

Hendel, I. and A. Lizzeri (1999b), "Interfering with Secondary Markets," RAND Journal of Economics, 30(1), 1-21.

Hendel, I. , A. Lizzeri and M. Siniscalchi (2005), "Efficient Sorting in a Dynamic Adverse-Selection Model," Review of Economic Studies, 72(2), 467-497.

House, C. and K. Leahy (2004), "An Ss Model with Adverse Selection," Journal of Political Economy, 112(3), 581-614.

Janssen, M. and S. Roy (2002), "Dynamic Trading in a Durable Good Market with Asymmetric Information," International Economic Review, 43(1), 257-282.

Johnson, J. and M. Waldman (2003), "Leasing, Lemons, and Buy-Backs," RAND Journal of Economics, 34(2), 247-265.

Kahn, C. (1986), "The Durable Goods Monopolist and Consistency with Increasing Costs," Econometrica, 54, 276-294.

Karp, C. (1996), "Depreciation Erodes the Coase Conjecture," European Economic Review, 40, 473-490.

Kim, J.-C. (1990), "Durable Good Monopoly with One-Hoss-Shay Depreciation," Economics Letters, 33(1), 1-4.

Konishi, H. and M. Sandfort (2002), "Existence of Stationary Equilibrium in the Markets for New and Used Durable Goods," Journal of Economic Dynamics and Control, 26(6), 1029-1052.

Palacios-Huerta, I. and A. Saracho (2004), "The Provision of Incentives in Durable Goods Firms," mimeo, Brown University.

Roberts, J. and H. Sonnenschein (1976), "On the Existence of Cournot Equilibrium without Concave Profit Functions," Journal of Economic Theory, 13, 112-117. 
Rust, J. (1985), "Stationary Equilibrium in a Market for Durable Assets," Econometrica, 53(4), 783-805.

Sobel, J. (1991), "Durable Goods Monopoly with Entry of New Consumers," Econometrica, 59, $1455-1485$.

Sobel, J. and I. Takahashi (1983), "A Multi-Stage Model of Bargaining," Review of Economic Studies, 50, 411-426.

Stokey, N. (1981), "Rational Expectations and Durable Goods Pricing," Bell Journal of Economics, 12, 112-128.

Stolyarov, D. (2002), "Turnover of Used Durables in a Stationary Equilibrium: Are Older Goods Traded More?" Journal of Political Economy, 110(6), 1390-1413.

Waldman, M. (1996), "Durable Goods Pricing When Quality Matters," Journal of Business, 69(4), 489-510.

Waldman, M. (2003), "Durable Goods Theory for Real World Markets," Journal of Economic Perspectives, 17(1), 131-154. 
Deneckere and Liang, Figure 1 of 5

Title: FIGURE 1. The Coase Conjecture Equilibrium

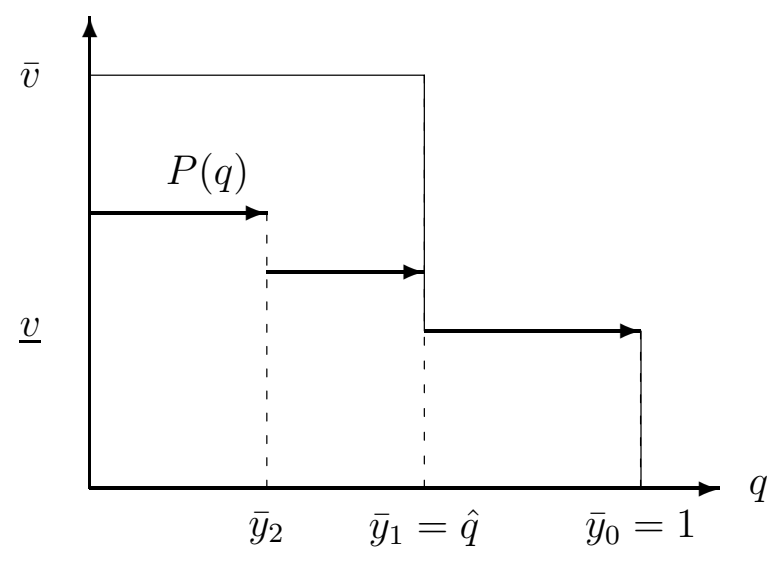


Deneckere and Liang, Figure 2 of 5

Title: FIGURE 2. The Monopoly Equilibrium
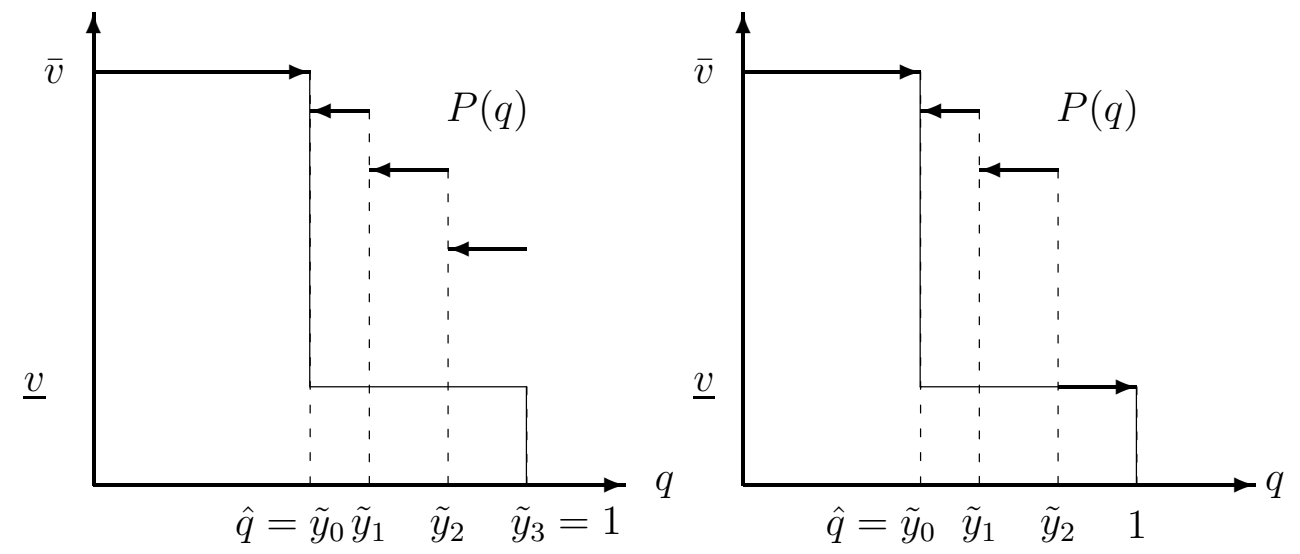
Deneckere and Liang, Figure 3 of 5

Title: FIGURE 3. The Reputational Equilibrium

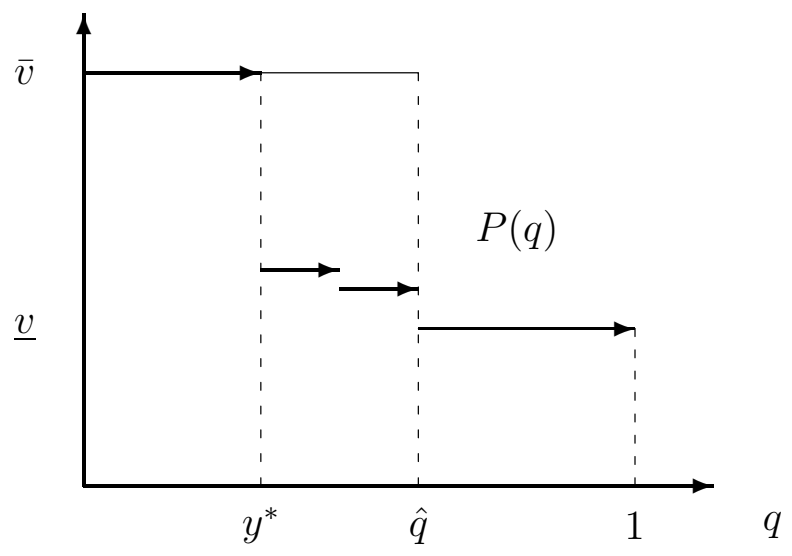


Deneckere and Liang, Figure 4 of 5

Title: FIGURE 4 . Range of $(\delta, \mu)$ where each equilibrium type exists

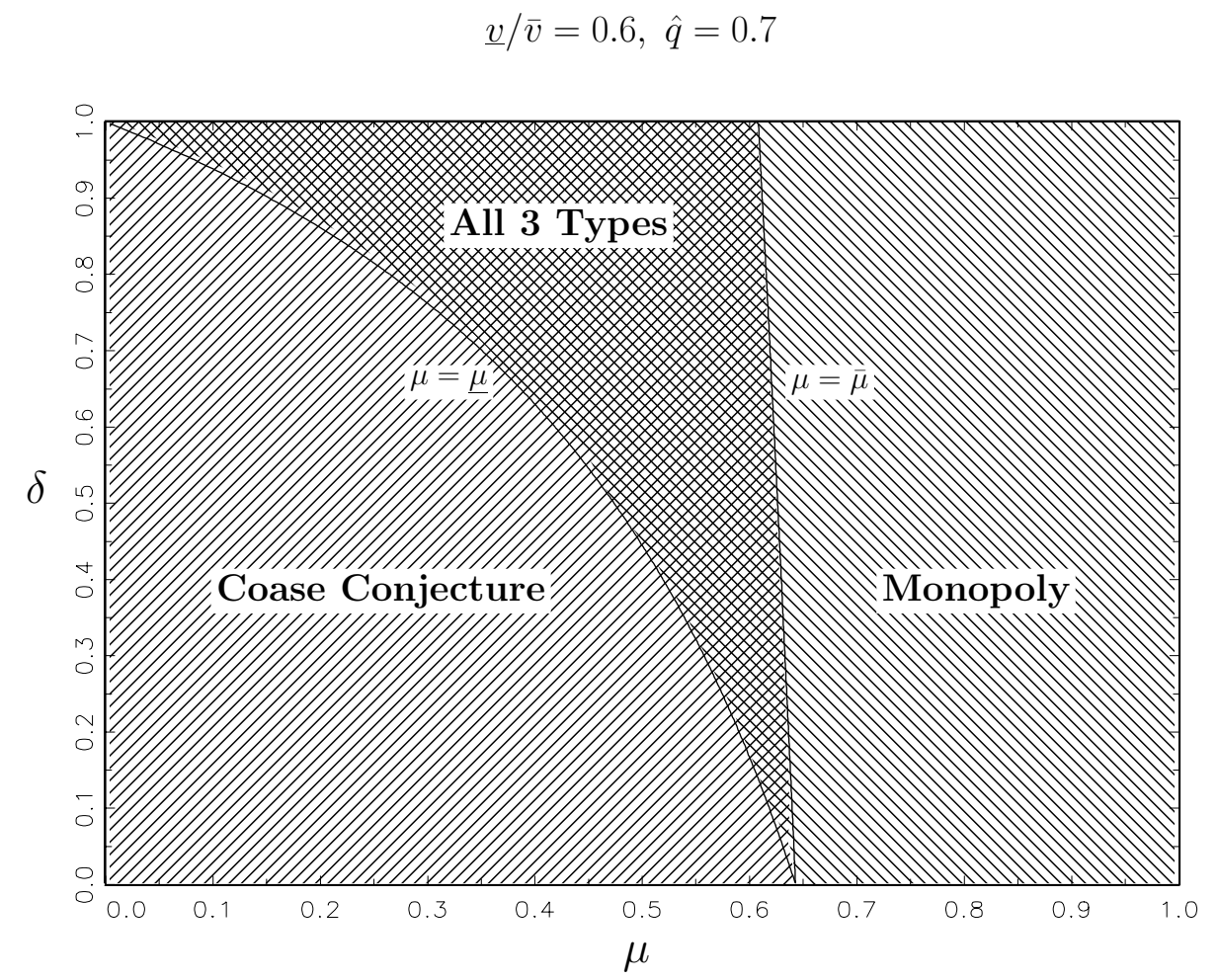


Deneckere and Liang, Figure 5 of 5

Title: FIGURE 5. Equilibrium profits as a function of $\mu$

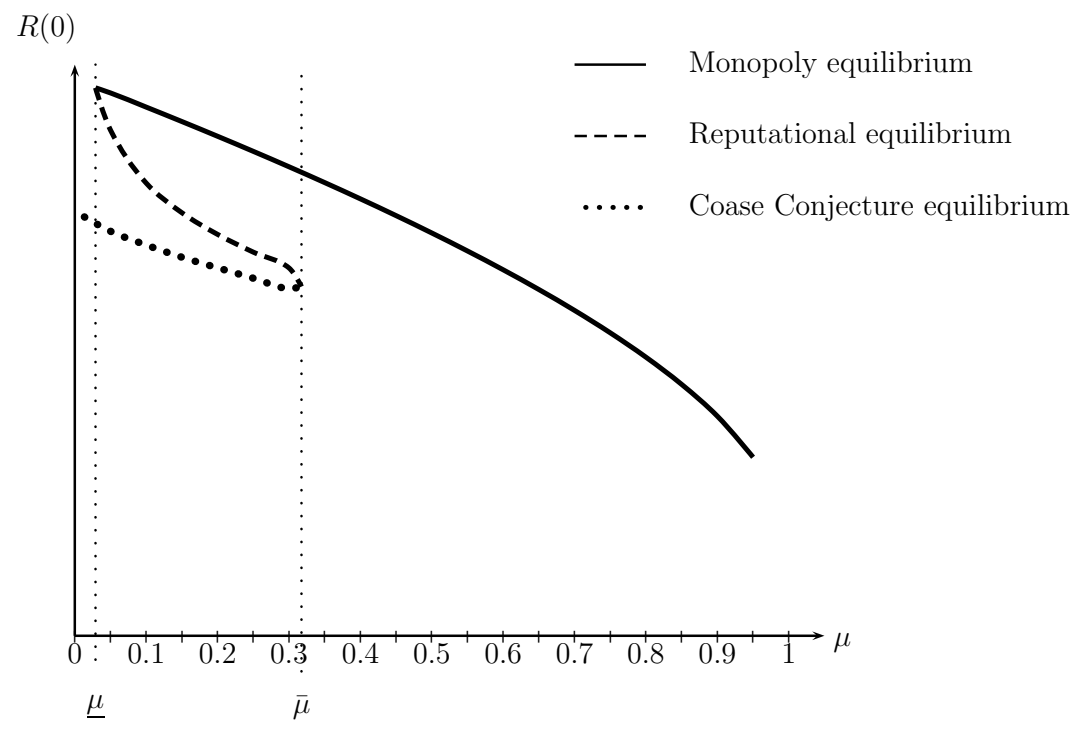

